\title{
Pediatric Neurology Workforce in Canada: A 5-Year Update
}

\author{
Lauren E. Strasser, Serena L. Orr, Hugh J. McMillan, Asif Doja, David J. A. Callen
}

\begin{abstract}
Background: In 2013, a task force was developed to discuss the future of the Canadian pediatric neurology workforce. The consensus was that there was no indication to reduce the number of training positions, but that the issue required continued surveillance. The current study provides a 5-year update on Canadian pediatric neurology workforce data. Methods: Names, practice types, number of weekly outpatient clinics, and dates of certification of all physicians currently practicing pediatric neurology in Canada were obtained. International data were used to compute comparisons between countries. National data sets were used to provide information about the number of residency positions available and the number of Canadian graduates per year. Models for future projections were developed based on published projected population data and trends from the past decade. Results: The number of pediatric neurologists practicing in Canada has increased 165\% since 1994. During this period, wait times have not significantly shortened. There are regional discrepancies in access to child neurologists. The Canadian pediatric neurology workforce available to see outpatient consultations is proportionally less than that of USA. After accounting for retirements and emigrations, the number of child neurologists being added to the workforce each year is 4.9. This will result in an expected 10-year increase in Canadian pediatric neurologists from 151 to 200. Conclusions: Despite an increase in the number of Canadian child neurologists over the last two decades, we do not predict that there will be problems with underemployment over the next decade.
\end{abstract}

RÉSUMÉ: Les effectifs en neurologie pédiatrique au Canada : une mise à jour tenant compte des cinq dernières années. Contexte : En 2013 , un comité de réflexion a été mis sur pied afin de discuter de l'avenir des effectifs canadiens en neurologie pédiatrique. Un consensus s'est alors dessiné : bien que rien n'indique qu'il faille réduire le nombre de places disponibles dans ce domaine de formation, cette question nécessite toutefois un suivi continu. La présente étude vise ainsi à offrir une mise à jour des données qui concernent ces effectifs en tenant compte des cinq dernières années. Méthodes : Les données suivantes ont été obtenues : noms des praticiens, types de pratique, nombre de consultations hebdomadaires en clinique externe et dates de certification de tous les médecins pratiquant actuellement la neurologie pédiatrique au Canada. Des données internationales ont également été utilisées pour effectuer des comparaisons entre divers pays. Des données au niveau national ont été rassemblées pour établir le nombre de places disponibles en résidence et le nombre de diplômés canadiens par année. Des modèles de projection ont aussi été élaborés en se fondant sur des projections de population déjà publiées et sur les tendances ayant marqué la décennie précédente. Résultats : Le nombre de neurologues pédiatriques qui pratiquent au Canada a augmenté de $165 \%$ depuis 1994. Fait à noter, les temps d'attente n'ont pas été notablement raccourcis durant cette période. Il existe aussi des disparités régionales en matière d'accès à cette spécialité de la neurologie. Les effectifs canadiens en neurologie pédiatrique disponibles pour des consultations en clinique externe demeurent proportionnellement moins importants qu'aux États-Unis. Après avoir tenu compte des départs à la retraite et des apports de l'extérieur, le nombre de neurologues pédiatriques ajoutés chaque année a été en moyenne de 4,9. Pendant une période de 10 ans, on anticipe donc qu'on devrait passer de 151 à 200 neurologues pédiatriques canadiens. Conclusions : En dépit d'une hausse du nombre de neurologues pédiatriques canadiens au cours des deux dernières décennies, nous ne prédisons pas de problèmes de sous-emploi au cours de la prochaine décennie.

Keywords: Workforce, Canada, Pediatric neurology, Resident training

doi:10.1017/cjn.2019.229

Can J Neurol Sci. 2019; 46: 566-574

\section{BACKGROUND}

In 2013, an expert panel of pediatric neurologists from across Canada met to discuss the availability of pediatric neurology positions in academic centers and community practice and to develop a consensus regarding how best to address workforce issues in pediatric neurology in Canada. ${ }^{1}$ At that time, the working group suggested closely monitoring workforce data over the subsequent 2-3 years. There were three core issues to be tracked: (1) the number of trainee positions offered, (2) community pediatric neurology positions as career options for graduates, and (3) the control of the residency positions in any given program. The current report provides an update on the state of the Canadian pediatric neurology workforce.

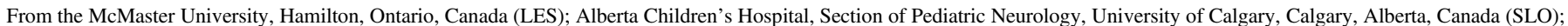

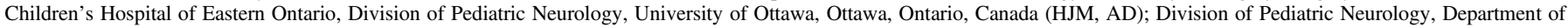
Pediatrics, McMaster Children's Hospital, McMaster University, Hamilton, Ontario, Canada (DJAC)

Received August 20, 2018. Final Revisions Submitted May 17, 2019. Date of Acceptance June 4, 2019.

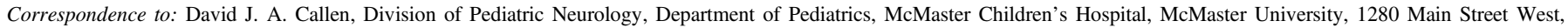
Hamilton, Ontario, L8S 4K1, Canada. Email: dcallen@mcmaster.ca 


\section{MethodS}

\section{Canadian Population Data}

The Canadian Census data from 1994, 2001, and 2016 were used to define the number of children in Canada, separated by province. $^{2-4}$ The total population data for each province was multiplied by the percentage found in the 0- to 16-year age ranges plus an additional 5\% for adolescents from 16 to 18 years of age.

\section{Past Canadian Pediatric Neurology Data}

Three previous studies published on the Canadian pediatric neurology workforce were used to acquire workforce data. ${ }^{1,5-7}$

\section{Current Canadian Pediatric Neurology Data}

The names and locations of all practicing child neurologists were initially acquired through provincial licensing bodies (e.g., College of Physicians and Surgeons). The practice type (academic, community, and hybrid) was determined based on affiliation with universities. All of these data were verified by representatives from each province. Average wait times for a "routine new patient" were provided directly to the authors by representatives from each center or community. Given that wait times apply to outpatient practice, the clinical outpatient full-time equivalent (FTE) value (i.e., the percentage of the neurologist's time spent seeing outpatients) was generated for each neurologist based on the number of half day clinics run on a weekly basis, as supplied by a representative from each center. Wait times and clinic numbers provided for each academic center were subsequently verified by an independent representative from that center. For community pediatric neurologists, clinics per week and wait times were verified for $23(82 \%)$ of 28 neurologists - the remaining 5 neurologists did not respond to repeated attempts at contact. Canadian regional clinical FTEs per 100,000 children were determined by calculating the sum of the individual clinical FTEs for each pediatric neurologist in the region, dividing that by the number of children in that region, and finally multiplying that value by 100,000 .

In order to determine the needs in the community, two questions were sent to all community pediatric neurologists across Canada. The questions were as follows: (1) Is there adequate clinical need in your area to keep you sufficiently busy? (2) Could your region use another pediatric neurologist?

\section{International Comparisons}

Previous publications were used to provide the numbers required for comparisons for the pediatric neurology workforce in the USA. ${ }^{8}$ Based on peer discussions, it was felt that the UK and Australia were other countries with comparable health-care systems. Given that no published data were available for the UK or Australia, the authors contacted representatives from the National Child Neurology Associations for each of these countries (Dr. Kate Riney, chief executive officer of the Australia and New Zealand Child Neurology Society; Dr. Alasdair Parker, national training advisor of the British Paediatric Neurology Association) and were provided with requested information.

Using the data provided by Polsky, ${ }^{8}$ the percentage of clinical hours for the American pediatric neurology Workforce was calculated by multiplying the percentage breakdown of practice type (33\% academic, $26 \%$ hybrid, and $39 \%$ community) by the average clinical outpatient FTE for each practice $(0.56,0.73$, and
0.84 , respectively) and then adding these values together. The optimal American clinical outpatient FTE per 100,000 children was determined by multiplying each percentage clinical outpatient FTE (as calculated above) by the total number of American pediatric neurologists in 2005 (reported to be 904), further multiplying this by 1.2 to add the additional $20 \%$ increase in the workforce recommended by those authors, ${ }^{8}$ and then finally dividing this product by the approximate number of children in the American population in 2005 (estimated to be 6,970,000). ${ }^{9}$

\section{Canadian Pediatric Neurology Training Data}

Published data regarding the number of Canadian pediatric neurology training program positions available were acquired from the Canadian Residency Matching Service. ${ }^{10}$ The number of Canadian pediatric neurology graduates and their current location of practice were derived from the directory of the Royal College of Physicians and Surgeons of Canada. ${ }^{11}$ Since these data did not differentiate adult and pediatric neurologists, the names were cross-referenced to the current pediatric neurology data (acquired as detailed above) as well as Internet searches to clarify the route of training as needed.

\section{Future Projections}

The approximate age of each pediatric neurologist across Canada was determined by establishing the date of Royal College certification. ${ }^{11}$ The estimated average age at certification used was 31 years (average age of graduation from secondary school $=17.5$ years + average years of undergraduate study $=4$ years + average years to complete medical school training $=4$ years + average time to complete pediatric neurology training $=5.5$ years). Given the variability of the route of study of each pediatric neurologist, 10-year ranges were used (i.e., estimated age \pm 5 years).

Retirement rates were estimated based on a probable age of retirement of 70 years. Future projections over the next 10 years were calculated by stipulating that all neurologists currently within the 60-year age range will likely retire within the next 10 years and dividing this number by 10 to determine the average number of retirements per year. The expected number of graduates each year was estimated using the average number of graduates over the past 5 years and subtracting the average number that do not practice pediatric neurology in Canada. A sensitivity analysis was performed changing the expected retirement rate and new graduate rate by $\pm 20 \%$, in order to provide for best/worst-case scenarios. The expected Canadian pediatric population in 2029 was calculated based on an estimated annual population growth of $0.86 \% .^{12}$

\section{Results}

\section{Canadian Population Data}

Based on the 2016 census, ${ }^{4}$ there are approximately 7.5 million children living in Canada. The number of children has increased over the past 20 years, with regional variability.

\section{Past Canadian Pediatric Neurology Workforce Data}

In 1994, a total of 57 pediatric neurologists were practicing in Canada (Figure 1). ${ }^{5}$ This resulted in a ratio of 0.8 pediatric 


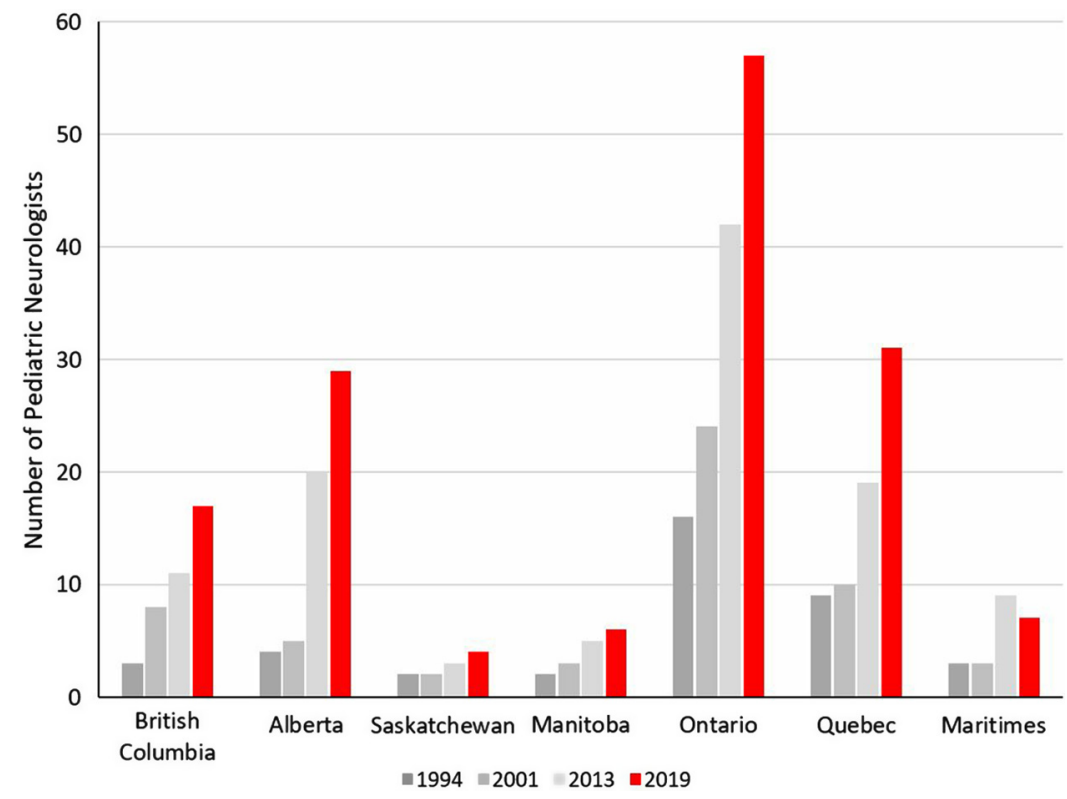

Figure 1: Number of practicing pediatric neurologists in Canada based on previous workforce publications from 1994, 2001, 2013, and current. ${ }^{1,5,7}$

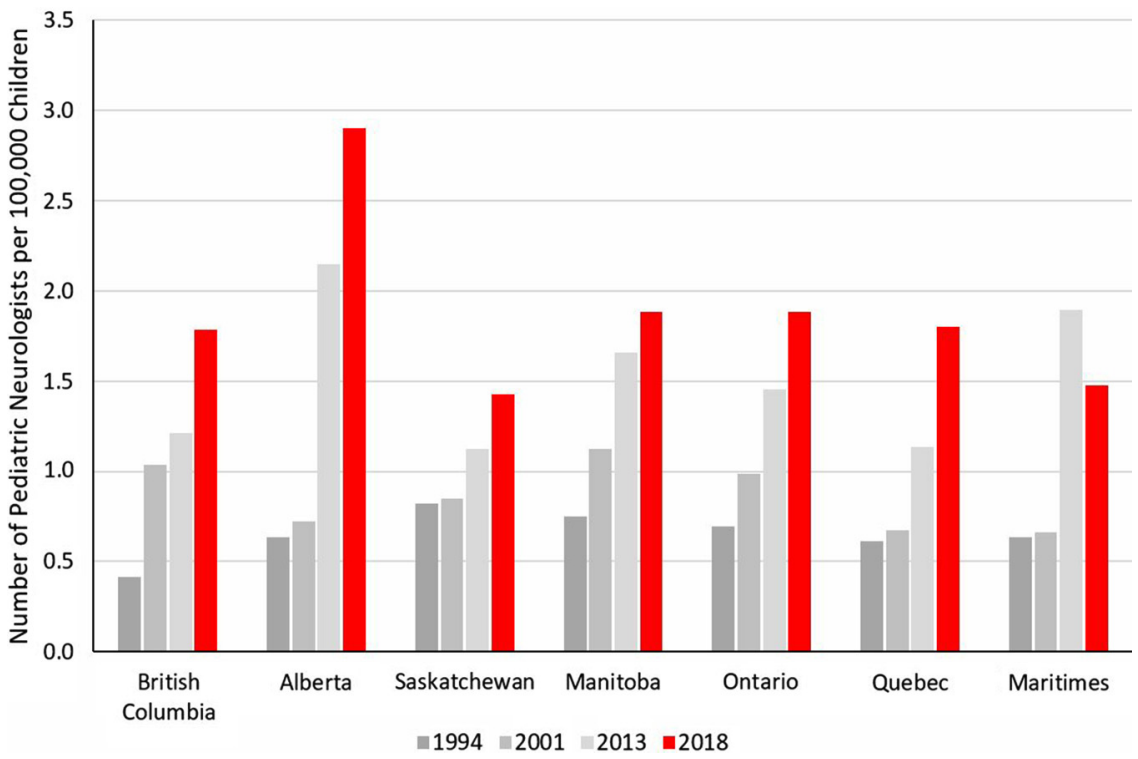

Figure 2: Number of practicing Canadian pediatric neurologists per 100,000 children based on previous workforce publications from 1994, 2001, 2013, and current. ${ }^{1,5,7,13}$

neurologists per 100,000 children, ranging from 0.4 in British Columbia to 1.0 in Saskatchewan (Figure 2). The number of graduating pediatric neurologists was estimated to be $1.6-2.5$ per year.

The study by Ronen and Meaney, published in 2003, stated that 63 FTE pediatric neurologists were practicing in Canada in $2000 .^{6}$ The number of FTE pediatric neurologists per 100,000 children (under the age of 15 years) was 1.1 across Canada, with a regional variation ranging from 0.7 in Alberta to 1.6 in Quebec. The average wait time to see a non-urgent new patient was 3 months (range: 3 weeks-18 months).
According to the study published by Keene and Humphreys in 2005 , there were a total of 80 pediatric neurologists practicing in Canada in $2001 .^{7}$ The ratio of pediatric neurologists to children was 1.0:100,000 [range: 0.7 (Quebec, Nova Scotia/Prince Edward Island) to 1.3 (Manitoba)]. The estimated number of graduating pediatric neurologists was 2-3 per year.

In 2013, the number of pediatric neurologists practicing in Canada was 127 full-time and 8 part-time. ${ }^{1}$ The average ratio of pediatric neurologists to children was 1.8:100,000 children (range: 1.1 (Saskatchewan) to 2.1 (Alberta)). The average wait time to see a routine new patient was 7.6 months (range: 3 months-2 years). 


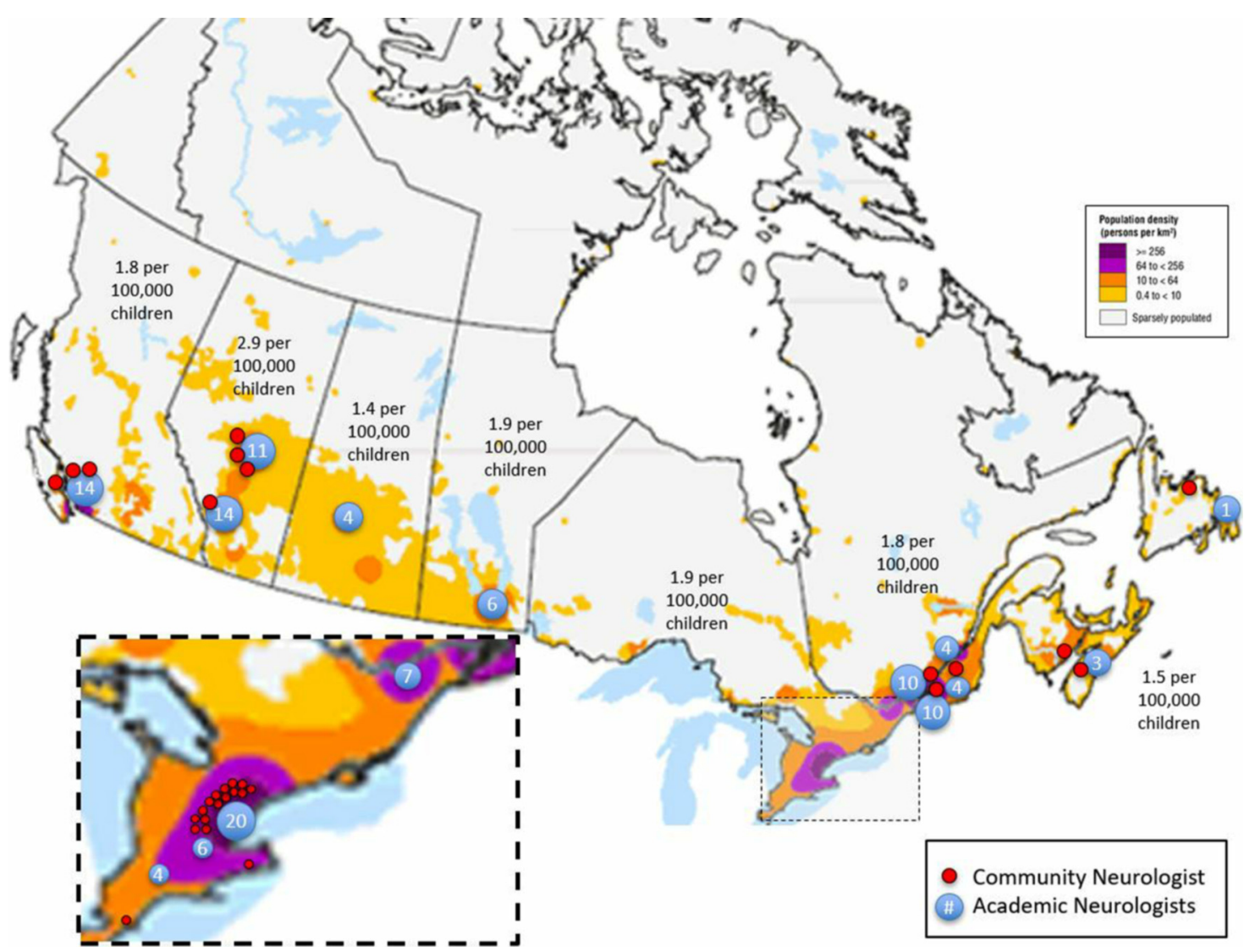

Figure 3: (Color online) Map of Canada showing relative population density. The number of pediatric neurologists per 100,000 children for each geographical region is displayed in text. The major academic centers are represented by blue circles with the number of pediatric neurologists practicing at that center displayed within. Community pediatric neurologists are each represented by a small red circle. The dashed rectangle over southern Ontario is displayed in the inset in the lower left of the figure for the sake of clarity.

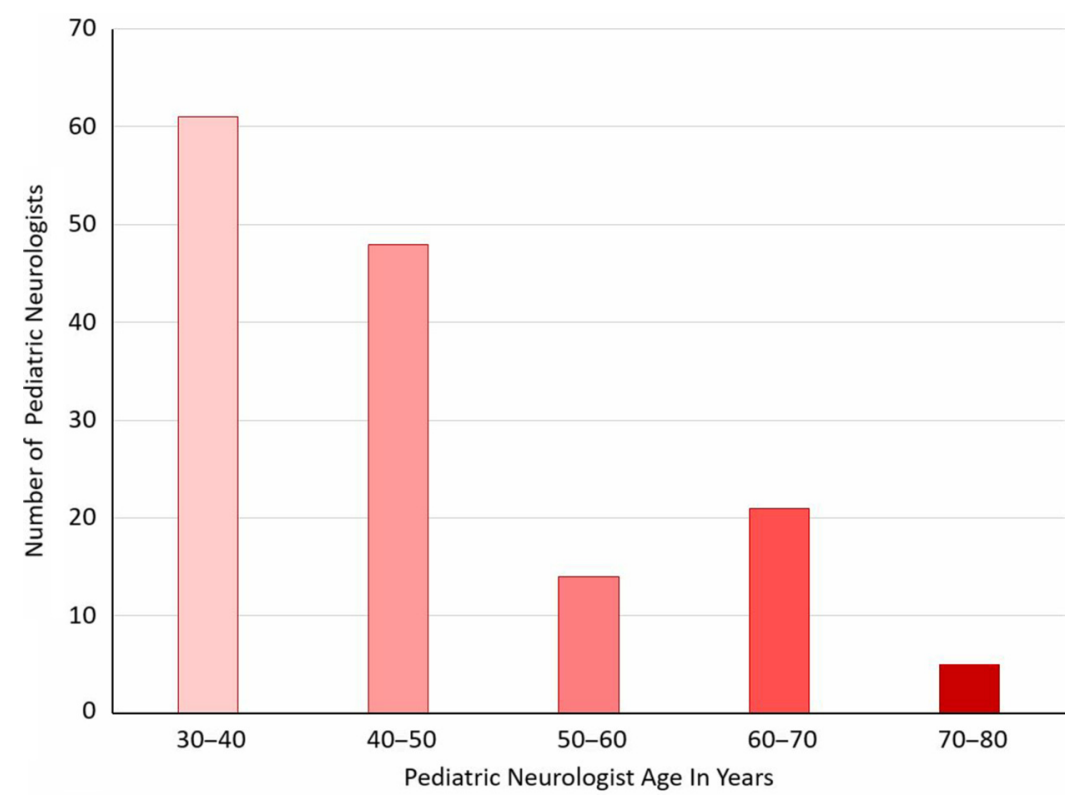

Figure 4: Estimated current age ranges of Canadian pediatric neurologists. 
Table 1: Mean wait times (in months) for routine new visit across Canadian provinces

\begin{tabular}{l|c|c|c}
\hline Location & $\mathbf{2 0 0 0}$ & $\mathbf{2 0 1 3}$ & $\mathbf{2 0 1 9 *}$ \\
\hline Maritimes & 3 & 3 & $10.4(4-12)$ \\
\hline Quebec & 5 & 5 & $6.6(5-8)$ \\
\hline Ontario & 8 & 6 & $6.5(1.5-24)$ \\
\hline Manitoba & 3 & 15 & $4(3-24)$ \\
\hline Saskatchewan & 3 & 24 & $7(6-8)$ \\
\hline Alberta & 7 & 5 & $5.2(1-12)$ \\
\hline British Columbia & 8 & 6 & $4.9(3-6)$ \\
\hline
\end{tabular}

*Numbers in parentheses represent range of wait times in months.

The estimated number of graduating pediatric neurologists was 11 per year.

\section{Current Canadian Pediatric Neurology Data}

At present, there are 151 child neurologists practicing in Canada. Among the current practicing pediatric neurologists, $81 \%$ work in academic centers and $19 \%$ in community practice (Figure 3). The number of community pediatric neurologists has doubled in the past 10 years and is largely based out of Ontario (55\%), mostly within the Greater Toronto Area. On average, neurologists in academic centers run 3.2 half day clinics per week, and neurologists in the community run 8.2 half day clinics per week (Supplementary Data). The estimated overall total clinical outpatient FTE for Canadian pediatric neurologists is 62 (i.e., 62 neurologists running 10 half-day clinics per week).

The average age of practicing pediatric neurologists is 41 years $( \pm 11.8$ years $)$, with 26 pediatric neurologists over 60 years of age (Figure 4 ).

The average wait time for a Canadian pediatric neurologist to see a routine new patient is 6.5 months. Wait times in Canada vary from province to province, with British Columbia currently having the shortest wait time (average $=5$ months) and Manitoba having the longest (average $>12$ months) (Table 1).

The two community pediatric neurology survey questions were sent to 31 individuals, with 16 responses. Eighty-three percent answered that there was adequate clinical need in their area to keep them sufficiently busy, and $71 \%$ answered that another pediatric neurologist could be helpful in their area. The regional pattern of responses suggested that limited additional need existed in the greater Toronto area and in Calgary.

\section{International Comparisons}

Compared to the other countries selected, Canada has the highest gross number of pediatric neurologists per 100,000 children (Table 2). The average wait time in Canada (198 days) is longer than that reported in other countries (70 days in the UK, 58 days in America). As expected, the models of practice differed significantly between countries, with $81 \%$ of Canadian pediatric neurologists practicing in academic centers, as opposed to only $33 \%$ of those in America. ${ }^{8}$ Based on the previous work by Polsky, ${ }^{8}$ American child neurologists not working in academic
Table 2: Comparison to other countries

\begin{tabular}{l|c|c|c|c}
\hline & Australia & $\begin{array}{c}\text { United } \\
\text { Kingdom }\end{array}$ & USA & Canada \\
\hline $\begin{array}{c}\text { Ratio of } \\
\text { practicing } \\
\text { pediatric } \\
\text { neurologists } \\
\text { per 100,000 } \\
\text { children }\end{array}$ & 1.1 & 0.7 & 1.3 & 1.9 \\
\hline $\begin{array}{c}\text { Average wait } \\
\text { time }\end{array}$ & - & 70 days & 58 days & 198 days \\
\hline Practice type & - & $100 \%$ & $33 \%$ & $81 \%$ \\
\hline Academic & - & - & $26 \%$ & - \\
\hline Hybrid & - & - & $39 \%$ & $19 \%$ \\
\hline Community & - & \multicolumn{3}{|c}{} \\
\hline
\end{tabular}

centers spend $73 \%$ (faculty) and $84 \%$ (non-faculty) of their time seeing patients, which is similar to that found in our study $(82 \%)$. When applied to the workforce, this suggests that, though the ratio of pediatric neurologists to children in Canada is higher than that in America, the effective clinical workforce hours are lower. The "optimal" American pediatric neurology clinical outpatient FTE was calculated to be 1.1 per 100,000 children. Canadian average clinical FTEs varied between provinces (Figure 5) but averaged 0.71 per 100,000 children overall.

\section{Canadian Pediatric Neurology Training Data}

In 2001, there was only one 5-year pediatric neurology residency position offered in Canada. The number of 3-year "fellowship" (i.e., after completing 3 years of general pediatric training) positions available was approximately 2-3 per year. By 2011, 10 residency positions and 2 fellowship positions were offered and filled. This amounts to an approximately $250 \%$ increase. Since 2011, an average of nine residency positions (80\% Canadian Medical Graduate positions, $20 \%$ International Medical Graduate positions) have been offered across Canada each year (Figure 6). The number of fellowship positions offered each year has varied significantly, ranging from one to four.

The number of residents completing training and becoming licensed to practice in Canada has displayed a similar increase (Figure 7). In the past 20 years, the number of graduates were 13 from 1998 to 2002, 21 from 2003 to 2007, 27 from 2008 to 2012, and 48 from 2013 to 2017 . This amounts to a $370 \%$ increase. Of the graduates, an average of $14 \%$ are not currently practicing pediatric neurology in Canada. These graduates either are practicing internationally or have changed specialties (e.g., developmental pediatrics, palliative care).

\section{Future Projections}

The estimated retirement rate over the next 10 years is expected to be 3.9 neurologists per year. The average number of graduates over the past 5 years was calculated to be 9.6 graduates per year, with an average of 0.8 graduates not practicing pediatric neurology in Canada. This results in 4.9 graduates per year being added to the Canadian workforce, after 


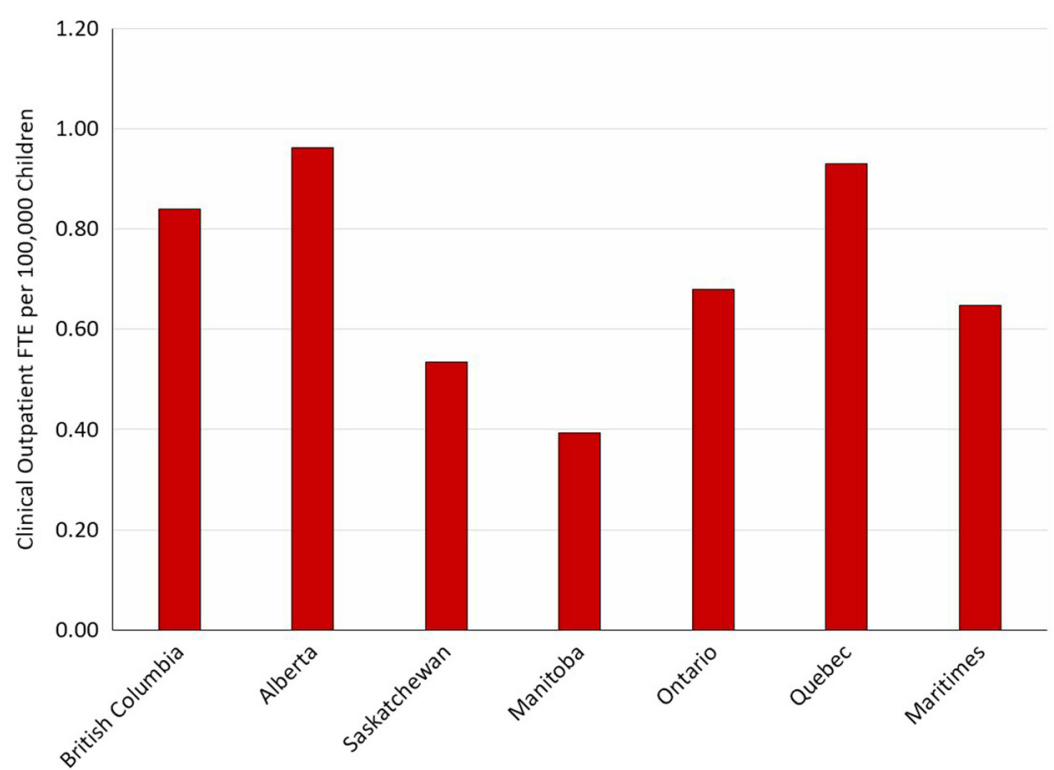

Figure 5: Current clinical outpatient full-time equivalent (FTE) per 100,000 children for each region of Canada.

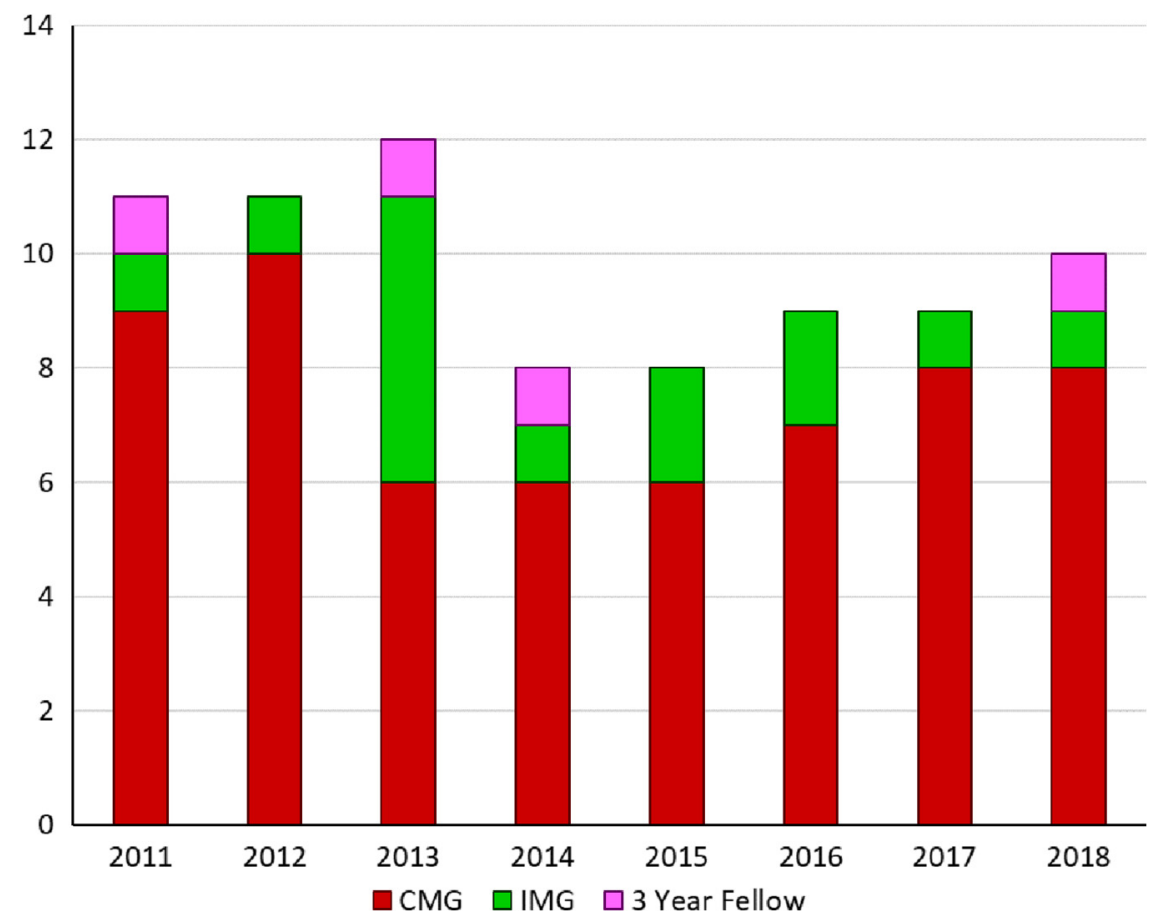

Figure 6: Trainees accepting into Canadian pediatric neurology residency programs since 2011. CMG - Canadian Medical Graduate; IMG = International Medical Graduate; 3-year fellow = already completed 3-4 years of residency in general pediatrics.

accounting for retirements and those choosing not to practice pediatric neurology in Canada. Applying this trend over the next 10 years results in a total of 200 pediatric neurologist practicing in Canada by 2029. Based on a sensitivity analysis examining scenarios with retirement rates and graduation rates varying $\pm 20 \%$, the total estimated number in 2029 could range from 172 to 228 . If no further academic positions were added, all of these graduates would practice in the community. If the average clinical outpatient FTE from community pediatric neurologists (0.82) is applied, this will result in an expected total clinical outpatient FTE of $102.2(79.2-125.1)$ or 1.2 (0.9-1.5) clinical outpatient FTE per 100,000 children. In an ideal situation, if an additional 10 academic positions were created in the next 10 years, this would result in an expected total clinical outpatient FTE of $97.2(74.2-120.1)$ or 1.2 (0.9-1.4) clinical outpatient FTE per 100,000 children. 


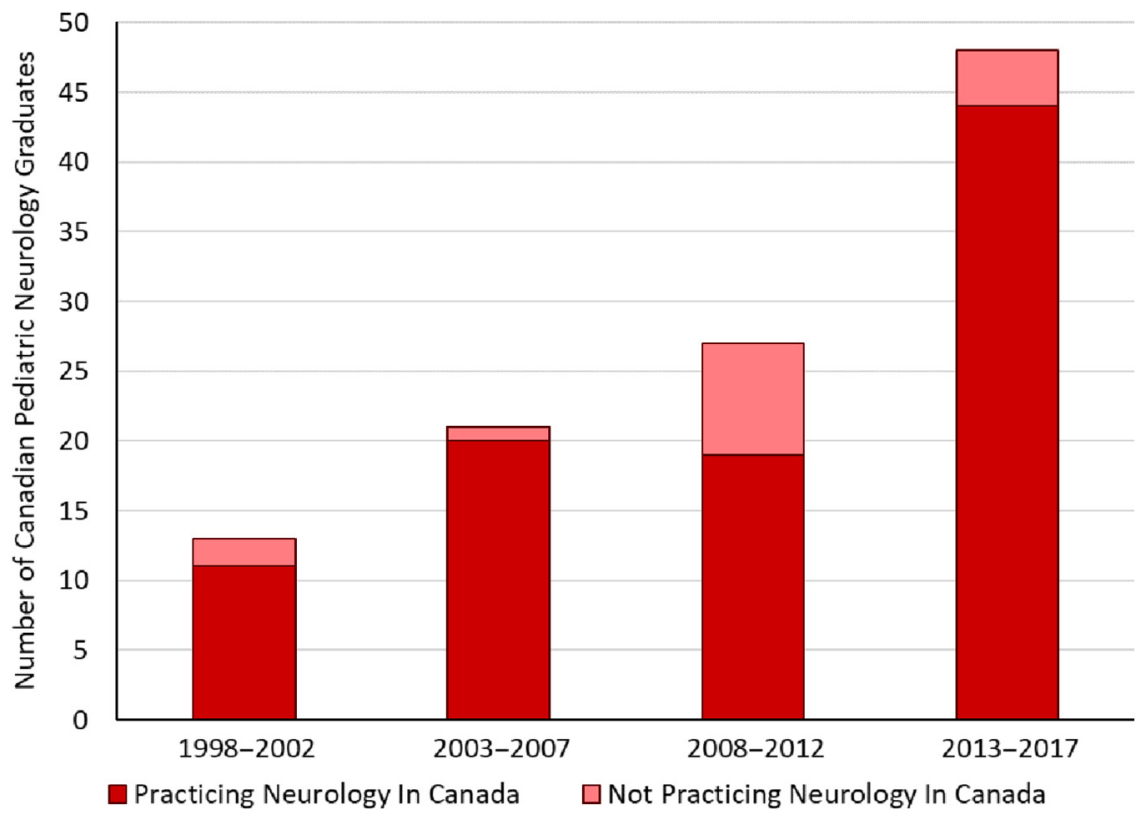

Figure 7: Total number of Canadian pediatric neurology graduates per 5-year span from 1998 to 2017. Those not practicing pediatric neurology in Canada may be practicing in another country or practicing a different specialty (e.g., developmental pediatrics).

\section{Conclusion}

This study provides an update on the status of the pediatric neurology workforce in Canada, building on numerous previous similar studies that have been published in the past. ${ }^{1,5-7}$

Since 1994, the number of pediatric neurologists in Canada has grown disproportionately when compared to the growth in the number of Canadian children ( $165 \%$ increase vs $27 \%$ increase). This increase is in alignment with the suggestions made by the authors of previous Canadian pediatric neurology workforce studies. $^{5-7}$

Despite the increase in the number of pediatric neurologists, there has not been a similar change in wait times for children to be seen. We hypothesize that this could be because of the high proportion of Canadian pediatric neurologists practicing in an academic center, where there is a high academic expectation, allowing for less time to be spent seeing outpatients. In addition, most pediatric neurologists in Canada have significant inpatient responsibilities and other clinical demands (such as reading electroencephalographs and epilepsy monitoring units) as well as participating in clinical trials, translational research, and in some cases basic science research, all of which can limit the proportion of time available for outpatient consultations. Taking this into account, despite the increase in the number of Canadian pediatric neurologists, the total time devoted to seeing outpatients remains lower than that of other countries, including the USA.

There continues to be significant regional variability in access to pediatric neurologists. We suspect that the reasons for this variability may be multifactorial and may include such factors as differences in remuneration, location of training, availability of academic positions, language differences as well as personal factors (e.g., location of family, ability of spouse to find employment in region, etc.). At present, the clinical outpatient FTE per 100,000 children is highest in Alberta and lowest in Saskatchewan.
This indicates a need for Canadian provinces to carefully examine their local workforce and population needs to optimally homogenize the access to child neurology services across Canada.

In workforce discussions, a question that often arises is "what is the optimal number of physicians necessary to best meet the needs of the population?" This would be best determined by accounting for a variety of factors including outpatient demands, inpatient service needs, and university academic/research goals, among other difficult-to-determine variables. The USA was the only country that had data to derive an optimal number of clinical outpatient pediatric neurology FTE, and this was derived from current numbers from 2005 plus the author's recommendation for a $20 \%$ increase in child neurologists in this country. As such, it is uncertain whether the number derived can be meaningfully applied to the Canadian workforce. If one were to use the optimal projected number based on this data (1.1 clinical outpatient FTE per 100,000 children), there remains room for growth in most regions of Canada (Figure 5).

An important concern raised by trainees in Canadian pediatric neurology programs, and medical students thinking about choosing a career in pediatric neurology, is whether they will be able to find employment at the end of their training. Based on our estimates, with our current training numbers, Canada is adding 4.9 pediatric neurologists to the workforce per year. While, based on our survey, there remains significant need for community pediatric neurologists in many areas of the country, some regions are already felt to be saturated. Given the substantial regional variability in clinical outpatient FTE per 100,00 children, it is essential for Canadian pediatric neurologists to develop a national strategic plan to encourage new graduates to practice in areas of need, such as Saskatchewan, Manitoba, and the Maritimes. Based on our data, these are regions where additional practicing pediatric neurologists would help reduce wait times and 
improve the neurological health of Canadian children. However, according to our 10-year projections, the expected clinical outpatient FTE for Canada in 2029 will be 1.2 (range $0.9-1.4)$ per 100,000 children, which will exceed the "optimal" value of 1.1 in Canada as a whole.

This raises the question of whether Canada should consider curtailing the training of child neurologists. Although this is a possible option, there are numerous alternative solutions. One solution would be to increase the number of academic positions available to new graduates, especially in underserved regions. This would not only result in a decreased national clinical outpatient FTE, given that academic pediatric neurologists see fewer outpatients compared to community neurologists, it would also allow for increased opportunities for academic productivity for pediatric neurologists practicing in regions that have high clinical demands. Another solution is for pediatric neurologists to broaden their scope of practice. Due to restricted workforce numbers in the past, many children with issues that perhaps should be seen by a pediatric neurologist, such as uncomplicated epilepsy, migraine, concussion, autism, learning disorders, have been managed by non-neurologists. In addition, though most Canadian child neurologists are licensed to follow patients beyond 18 years of age, they have traditionally not done so, in part, due to the high patient volumes and low numbers of child neurologists. Many young adults with complex pediatric neurological issues, such as rare genetic/metabolic syndromes, could potentially continue to be followed by their pediatric neurologist into their 20s, rather than being transitioned to adult neurology care. Finally, given the societal shift to accommodate pediatric neurologists practicing only part-time as well as the contributions of parental leaves, sick leaves, and sabbaticals, it may be that the number of additional clinical outpatient FTEs predicted will actually be less than expected.

Our study has a number of limitations. As discussed above, we were unable to determine a realistic optimal number of child neurologists to best serve the Canadian population, given the varied roles child neurologists play. For example, how many child neurologists are required to maintain our current national level of research achievement? How many child neurologists are required to adequately educate medical students, residents, and fellows, especially in the context of the changing landscape of medical education in Canada? Unfortunately, we have no metrics to encompass these concepts. We have also made assumptions about expected retirement rates, development of new academic positions, and immigration/emigration of pediatric neurologists. In addition, the metric of clinical outpatient FTE is inadequate to capture clinical diversity. General child neurologists in some areas of the country do not see "routine" consults (e.g., migraine, tics, developmental delay), while some see such consults regularly. How can one then answer the question of the average time to see a "routine" consult. Many pediatric neurologists have subspecialized and, thus, see only patients with certain conditions (e.g., epilepsy, stroke) referred to them from other child neurologists. Although these subspecialists are running outpatient clinics, their clinical outpatient FTE may have little meaning for the wait time for a patient in the community to be seen by a child neurologist. We also acknowledge that there is regional variability in need for child neurologists that is not reflected by the future projections predicting an overall clinical outpatient FTE surplus in 10 years. Given all of these limitations, inter- pretation of the data is challenging, but, in our opinion, this is true of all such studies published previously in this field both in Canada and in other countries.

In conclusion, there has been a substantial increase in the number of pediatric neurologists practicing in Canada over the past 20 years, without commensurate growth in academic positions. However, provided that the current practice landscape of pediatric neurology in Canada can adapt to the changing workforce patterns, we do not predict a lack of employment imminent for graduates within the next 10 years. We would propose that the increased number of neurologists will not only decrease wait times by establishing more presence in the community but allow for more optimal care of Canadian children and young adults with neurological disorders.

\section{ACKNOWLEDGEMENTS}

The authors would like to thank Drs. Kate Riney and Alasdair Parker for supplying the data from Australia and the UK. The authors would also like to thank Drs. Linda Huh, Kathryn Selby, Aleksandra Mineyko, Adam Kirton, Jong Rho, Francois Jacob, Richard Huntsman, Megan Crone, Samantha Marin, Edward Leung, Kaitlyn Muir, Craig Campbell, Robyn Whitney, Dragos Nita, Chintan Shah, Kaitlyn Siu, Oksana Borys, Salma Remtulla, Hema Gangam, Elisabeth Simard-Tremblay, Paola Diadori, Genevieve Lagault, Philippe Major, Emilie Riou, Paula Brna and Muhammad Alam for providing and/or verifying data.

\section{Disclosure}

The authors report no conflicts of interest.

\section{Statement of Authorship}

DJAC collected and analyzed the data and revised the re-submitted manuscript; LES wrote the originally submitted manuscript; SLO, AD, and HJM were part of the Canadian Pediatric Neurology working group (in 2013), were coauthors of the previous publication (2016), and reviewed the manuscript the current originally submitted manuscript as well as the revised version.

\section{Supplementary Material}

To view supplementary material for this article, please visit https://doi.org/10.1017/cjn.2019.229.

\section{REFERENCES}

1. Doja A, Orr SL, McMillan HJ, et al. Canadian paediatric neurology workforce survey and consensus statement. Can J Neurol Sci. 2016;43:402-9.

2. Data tables, 1996 Census, Statistics Canada [online]. Available at: https://www12.statcan.gc.ca/datasets/Index-eng.cfm.

3. Data tables, 2001 Census, Statistics Canada [online]. Available at: https://www12.statcan.gc.ca/datasets/Index-eng.cfm.

4. Data tables, 2016 Census, Statistics Canada [online]. Available at: https://www12.statcan.gc.ca/census-recensement/2016/dp-pd/ index-eng.cfm.

5. Keene DL, Humphreys P. Pediatric neurology manpower requirements. Ann RCPCSC. 1997;30:165-8.

6. Ronen GM, Meaney BF. Pediatric neurology services in Canada: demand versus supply. J Child Neurol. 2003;18:180-4. 
7. Keene DL, Humphreys P. Inventory of pediatric neurology "manpower" in Canada. Can J Neurol Sci. 2005;32:306-10.

8. Polsky D. Child neurology: workforce and practice characteristics. LDI Issue Brief. 2005;10:1-4.

9. Data tables, 2005, United States Census Bureau [online]. Available at: https://www.census.gov/data/tables/2005/demo/age-and-sex/ 2005-age-sex-composition.html.

10. R-1 Data and reports, Canadian Resident Matching Service [online]. Available at: https://www.carms.ca/data-reports/r1-data-reports/.
11. Directory, Royal College of Physicians and Surgeons of Canada [online]. Available at: https://rclogin.royalcollege.ca/webcenter/ portal/rcdirectory_en.

12. Annual Demographics Estimates: Canada, Provinces and Territories, 2018 [online]. Available at: https://www150.statcan.gc.ca/ n1/pub/91-215-x/2018001/sec1-eng.htm.

13. Canada at a Glance 2017, Statistics Canada [online]. Available at: https://www150.statcan.gc.ca/n1/pub/12-581-x/2017000/popeng.htm. 